DOI: $10.35643 /$ Info. 25.2 .5

Artículo original

\title{
Identificación, representación descriptiva y evaluación archivísticas a partir de imágenes digitalizadas de documentos microfilmados que integran los llamados Archivos Berrutti del Ministerio de Defensa Nacional del Uruguay
}

Identification, descriptive representation and archival appraisal from digitized images of microfilmed documents which make up the so-called Berrutti Archives of the Ministry of Defense National in Uruguay

Identificação, representação descritiva e avaliação arquivística a partir de imagens digitalizadas de documentos microfilmados que compõem os chamados Arquivos Berrutti do Ministério de Defesa Nacional do Uruguai

Fabián Hernández Muñiz ${ }^{\mathrm{a}}$ María del Luján López ${ }^{\text {b }}$ Telma Orcesi ${ }^{\mathrm{c}}$

a Profesor Adjunto del Departamento Fuentes Documentales, Recursos y Servicios de Información, Instituto de Información, Facultad de Información y Comunicación, Universidad de la República, Uruguay. Correo electrónico: fabian.hernandez@fic.edu.uy. ORCID 0000-00032173-3417.

b Docente Asistente del Departamento Fuentes Documentales, Recursos y Servicios de Información, Instituto de Información, Facultad de Información y Comunicación, Universidad de la República, Uruguay. Correo electrónico: maria.lopez@fic.edu.uy. ORCID 0000-0003-2734$\underline{6207}$.

${ }^{c}$ Docente Ayudante del Departamento Tratamiento y Transferencia de Información, Instituto de Información, Facultad de Información y Comunicación, Universidad de la República, Uruguay. Correo electrónico: telma.orcesi@ fic.edu.uy. ORCID 0000-0002-7551-1185.

\section{Resumen}

Se presenta el proyecto denominado Identificación archivística de tipos y series documentales a partir de imágenes digitalizadas de documentos microfilmados que integran los llamados Archivos Berrutti, el cual surge de las actividades de investigación en el área de archivología realizadas en la Facultad de Información y Comunicación de la Universidad de la República de Uruguay. Constituye un componente de la línea de investigación Recursos de Investigación Digital, en tanto presenta interés en la tipología de los recursos de información digitales. El objetivo es proponer pautas desde la investigación archivística para el tratamiento de identificación, representación descriptiva y evaluación de las imágenes digitalizadas de documentos microfilmados que integran los Archivos Berrutti del Ministerio de Defensa Nacional del Uruguay. La metodología definida presenta 
un enfoque cualitativo de tipo exploratorio y descriptivo apropiado para cumplir con los objetivos planteados. Los resultados de la investigación pretenden brindar un abordaje archivístico con el desarrollo de funciones específicas sobre una agrupación documental con características especiales.

Palabras clave: IDENTIFICACIÓN ARCHIVÍSTICA; DESCRIPCIÓN ARCHIVÍSTICA; EVALUACIÓN ARCHIVÍSTICA; ARCHIVOS BERRUTTI; URUGUAY.

\begin{abstract}
It presents the project Archival identification of types and documentary series from digitized images of microfilmed documents that make up the so-called Berrutti Archives, which arises from the research activities in the area of archival science carried out at the Faculty of Information and Communication of the University of the Republic of Uruguay. It constitutes a component of the Digital Research Resources research line, as it shows interest in the typology of digital information resources. The objective is to propose guidelines from archival research for the treatment of identification, descriptive representation and evaluation of the digitized images of microfilmed documents that make up the Berrutti Archives of the Ministry of National Defense of Uruguay. The defined methodology presents a qualitative, exploratory and descriptive approach appropriate to meet the objectives set. The results of the research are intended to provide an archival approach with the development of specific functions on a documentary grouping with special characteristics.
\end{abstract}

Keywords: ARCHIVAL IDENTIFICATION; ARCHIVAL DESCRIPTION; ARCHIVAL APPRAISAL; BERRUTTI ARCHIVES; URUGUAY.

\title{
Resumo
}

Apresenta-se o projeto denominado Identificação arquivística de tipologias e séries documentais a partir de imagens digitalizadas de documentos microfilmados que integram os chamados Arquivos Berrutti, que surge a partir das atividades de investigação na área da arquivologia desenvolvidas na Faculdade de Informação e Comunicação do Universidade da República do Uruguai. Constitui um componente da linha de pesquisa Recursos de Pesquisa Digital, pois mostra interesse pela tipologia dos recursos de informação digital. O objetivo é propor diretrizes da pesquisa arquivística para o tratamento da identificação, representação descritiva e avaliação das imagens digitalizadas dos documentos microfilmados que compõem o Arquivo Berrutti do Ministério da Defesa Nacional do Uruguai. A metodologia definida apresenta uma abordagem qualitativa, exploratória e descritiva adequada ao cumprimento dos objetivos traçados. Os resultados da investigação pretendem proporcionar uma abordagem arquivística com o desenvolvimento de funções específicas num agrupamento documental com características especiais.

Palavras-chave: IDENTIFICAÇÃO ARQUIVÍSTICA; DESCRIÇÃO ARQUIVÍSTICA; AVALIAÇÃO ARQUIVÍSTICA; BERRUTTI FILES; URUGUAI. 
Fecha de recibido: $\quad$ 12/09/2020

Fecha de aceptado: $\quad 03 / 11 / 2020$

\section{Introducción}

El presente trabajo surge de las actividades de investigación en el área de archivología realizadas en la Facultad de Información y Comunicación (FIC) de la Universidad de la República de Uruguay. Allí, se desarrollan líneas de investigación iniciadas en el marco del proyecto de extensión universitaria en derechos humanos el cual lleva como título Sistematización, tratamiento y difusión de la información digital vinculada con las investigaciones en materia de graves violaciones a los derechos humanos en el pasado reciente y terrorismo de Estado (en adelante, referenciado como Cruzar.uy). Se materializa en una propuesta presentada en el llamado 2017 de la convocatoria a proyectos de extensión en derechos humanos de Comisión Sectorial de Extensión y Actividades en el Medio (CSEAM). Particularmente, para este caso, en la temática Pasado reciente y terrorismo de estado: verdad, justicia, memoria y reparación.

En ese sentido, el surgimiento del grupo de trabajo Cruzar.uy reside en el interés de docentes de la FIC, tanto de las áreas de información como de comunicación junto con docentes del Instituto de Computación (INCO) de la Facultad de Ingeniería (FING), quienes, en diálogo con algunos representantes de la organización civil de Madres y Familiares de Uruguayos Detenidos Desaparecidos comienzan a trazar una propuesta para atender a la necesidad del cruzamiento de datos a partir de la sistematización de la información digital de archivos militares, policiales y del Estado en general.

En ese sentido, los archivos de la represión se corresponden con el

conjunto de objetos secuestrados a las víctimas o producidos por las fuerzas de seguridad (policías, servicios de inteligencia, fuerzas armadas) en acciones represivas (allanamientos, persecución, secuestros, tortura, desaparición, asesinatos, etc.) perpetradas durante las últimas dictaduras militares en los países del Cono Sur (Da Silva Catela, 2002, p. 395).

A nivel documental, las agrupaciones constituidas se convierten en patrimonio archivístico que ha de ser preservado con atención en aquellas medidas técnicas 
que garanticen su integridad y conservación a largo plazo, en tanto pasan a conformar una parte de la memoria de la nación y de la humanidad respecto a regímenes políticos totalitarios que han marcado un período determinado de la historia de los pueblos.

Por su parte, Caroline Bauer (2014) define a los archivos de la represión como los

conjuntos documentais produzidos pelos órgãos de informação e seguranças em ações repressivas durante a vigência das ditaduras civil-militares de segurança nacional. Os dados neles contidos eram de fundamental importância para a consecução das estratégias de implantação do terror, evidenciando a relevância que a informação adquiria para esses regimes, e orientando a execução das operações militares e policiais (p. 265).

Dentro de esa clase de archivos se encuentran aquellos constituidos y conservados por las propias fuerzas armadas y las de seguridad policial que responden a las competencias y funciones de información e inteligencia de la época. Por consiguiente, archivos de inteligencia militar y policial respectivamente.

Específicamente para el presente estudio investigativo, la delimitación cronológica para Uruguay corresponde a aquellas imágenes digitalizadas de documentos producidos en el periodo comprendido entre 1968 y 1985 o, incluso, documentación excedida de esta delimitación temporal, pero con implicación y vinculación en su contenido informacional. La documentación original concierne al acopio de información por parte de una entidad represiva de la época, que centralizó el proceso de microfilmación de documentos procedentes de diversas áreas de información e inteligencia, así como de distintos órganos internos del Ministerio de Defensa Nacional, y/o provenientes de otras entidades del Estado. Como premisa general, el presente proyecto complementa los objetivos principales que dieron inicio al proyecto Cruzar.uy centrados en el ejercicio académico de, a partir de la información digital producto de procesos de digitalización documental, la aplicación de las funciones archivísticas, la optimización del procesamiento de imágenes y la concentración en una base de datos que permita el cruzamiento de información. De esta manera, contribuir a la búsqueda de la verdad con las investigaciones de la justicia para el esclarecimiento de los hechos atentatorios a las dignidades humanas sucedidas a instancias de la actuación ilegítima y terrorismo de estado en el Uruguay. 
En la línea del objetivo dirigido a la identificación y análisis de los contenidos en soporte digital surge un proyecto específico en el área de la Ciencia de la información, especialmente en la licenciatura de archivología, bajo la denominación de Identificación archivística de series documentales a partir de imágenes digitalizadas de documentos microfilmados que integran los llamados Archivos Berrutti (en adelante, referenciado como IdArchi-Cruzar.uy).

Este proyecto específico se anida con componentes de alcance investigativo de Recursos de Investigación Digital (RID), en tanto es una sublínea de investigación que se desarrolla en el marco de unidades curriculares de las licenciaturas en archivología y bibliotecología de la FIC, integrada en el Departamento Fuentes Documentales, Recursos y Servicios de Información.

El objetivo general de RID se dirige a identificar, analizar y evaluar los recursos de información digitales, generados en cualquiera de las modalidades de producción documental e información digital, sean por conversión de soporte o nacidos digitalmente.

A ese respecto, la línea alcanza a la diversidad de tipologías documentales que se producen y merece un estudio sobre las características de cada una que permita una identificación según sus propiedades y particularidades. Al mismo tiempo, aumenta la complejidad que adquieren estas tipologías en el entorno digital, siendo necesario un análisis en profundidad que contemple también criterios para su evaluación. Aspectos sustanciales en un enfoque archivístico contemporáneo, en consideración con la concepción de las funciones archivísticas establecida por Carol Couture

Como disciplina, a arquivística canadense definiu um conjunto de funções que lhe são próprias e que se fundamentam na realidade das intervenções do arquivista. Baseadas numa análise das necessidades, a racionalização da produção de documentos, a avaliação, a aqui-sição (crescimento), arranjo, descrição, difusão e preservação são as funções que consideramos como conquistas para a disciplina arquivística (Couture, 2015, p. 152).

Para el desarrollo de IdArchi-Cruzar.uy corresponde presentar un abordaje teórico conceptual de las funciones que darán respaldo a la investigación en el área archivística sobre imágenes digitales de documentos vinculados con las violaciones a los derechos humanos ocurridos en el período de actuación ilegítima y terrorismo de estado en el Uruguay. 
La función del documento como prueba, registro de información documentada, así como el archivo, en tanto representación de una realidad social, son las bases de este ejercicio de reconstrucción de eventos (hechos, momentos particulares) y la conjunción de entidades en un escenario vivido de la historia del Uruguay.

Quando se pensa o documento na contemporaneidade, um dos entendimentos possíveis diz respeito ao suporte que contém alguma informação de valor social e/ou institucional. Por institucionalidade se entende a objetivação de atributos ou de valor ao objeto por aqueles que produzem, armazenam ou utilizam. Em cada contexto, o documento pode apresentar funções das mais diversas (ensinamento, instrução, prova, dentre outros) próprias a sua criação ou atribuídas a posteriori (Rabello y Rodrigues, 2017, p. 33).

Desde esa perspectiva, los documentos de archivo adquieren un interés especial para la investigación y el conocimiento del pasado histórico de una sociedad.

González Quintana reflexiona al respecto:

a menudo se menciona la importancia de que los documentos generados en torno a la represión política tienen para perpetuar la memoria de los pueblos, porque son un testimonio insustituible de la represión que han sufrido. Pero el argumento más importante para defender la conservación de los documentos represivos en la nueva democracia radica en la importancia que tienen las personas afectadas por la represión como víctimas, ya que serán esenciales en la nueva situación política para el ejercicio de ciertos derechos individuales: la rehabilitación, la amnistía, reparaciones. indemnizaciones, pensiones, la restitución de los bienes (González Quintana, 2012, p. 216).

En relación con la función de identificación archivística, corresponde señalar que ese sintagma nominal se encuentra en la literatura desde los años 80, y los conceptos establecidos en diccionarios de terminología archivística de España y

Brasil en los años 1990 y 2005 son resumidos por Ana Celia Rodrigues como

fase do processamento técnico, de tipo intelectual, que tem por objeto de estudos o órgão produtor e os documentos gerados no exercício de suas atividades. O conhecimento produzido nesta fase de pesquisa fica registrado em instrumentos específicos e fundamentam o desenvolvimento das funções de planejamento da produção, classificação, avaliação e descrição de documentos de arquivo (Rodrigues, 2011, p. 559).

Esta fase de la metodología archivística "consiste em estudar analiticamente o documento de arquivo e os vínculos que mantém com o órgão que o produziu, seja em fase de produção ou de acumulação", como explica Rodrigues, se trata de un trabajo de investigación y de crítica sobre la génesis documental (Rodrigues, 2011, p. 560). 
Una segunda función para destacar en este proyecto, directamente relacionada con la representación descriptiva, es la descripción archivística, que la profesora Dra. Antonia Heredia define como

función archivística que forma parte de la gestión documental y consiste en elaborar representaciones de documentos de archivos, de agrupaciones documentales y de otras entidades archivísticas (agentes, funciones, normas, lugar) a partir de sus atributos para facilitar el acceso de los usuarios a la información contextualizada de sus contenidos (Heredia, 2011, p. 84).

Por otra parte, Dunia Llanes Padrón conceptualiza a la descripción como el

elaborar una representación (actividad) que puede tener diferentes formas de manifestación (instrumentos de consulta); a partir de una base de datos descriptiva es posible obtener diferentes formatos de salida (varias formas de visualización en pantalla o distintos tipos de impresos) (Llanes Padrón, 2016, p. 27).

En base a las anteriores definiciones la representación de la información de los conjuntos documentales que integran el acervo de una entidad archivo, en este caso especializada en el área de los derechos humanos, es fundamental para la preservación y el acceso a los documentos de archivo. Así como para la gestión de la información archivística contenida en los procesos de búsqueda de la verdad, la justicia, las investigaciones en la materia y para la construcción de la memoria.

Este tipo especializado de archivos está vinculado con la memoria colectiva de personas que han sido protagonistas de un traumático hecho histórico como fueron las graves violaciones a los derechos humanos en el pasado reciente y terrorismo de Estado, así como con la producción de documentos específicos de ese entorno.

En ese sentido, Pedro López López (2014) afirma que

en el contexto de la memoria histórica, la información es necesaria para el ejercicio del derecho individual y colectivo a la verdad, para el derecho a la justicia y el derecho a la reparación. Si no tenemos información sobre hechos y responsables de esos hechos, se hace imposible articular una reclamación de estos derechos. Por otro lado, el derecho a la información es un pilar básico de la democracia porque el Estado está obligado a dar publicidad de su actividad, la transparencia debe regir los procedimientos administrativos y las actuaciones del gobierno (López López, 2014, p. 3).

Para llevar a cabo el trabajo descriptivo se debe recurrir a estándares normalizados, tanto la Norma Internacional General de Descripción Archivística (ISAD-G), como la Norma Uruguaya de Descripción Archivística (NUDA), a las que 
se recurren para describir las entidades documentales, su posterior recuperación y así poder utilizar e intercambiar su información.

Las descripciones efectuadas de esta manera permiten el control intelectual para que las mismas sean fiables, auténticas, significativas y accesibles, además de mantenerse a través del tiempo (ICA, 2000, p. 12).

La ISAD-G, estándar de estructura de datos que permite normalizar la descripción de la entidad documento de archivo y además se encuentra dividida en siete áreas de información descriptiva en las que se distribuyen veintiséis (26) elementos, combinables entre sí, a saber:

1. Área de Identificación que contiene la información específica para identificar la unidad de descripción;

2. Área de Contexto que contiene la información referente al origen y custodia de la unidad de descripción;

3. Área de Contenido y Estructura que contiene información concerniente al objeto y organización de la unidad de descripción;

4. Área de Acceso y Utilización que contiene la información relativa a la accesibilidad de la unidad de descripción;

5. Área de Documentación Asociada que contiene la información relativa a aquellos documentos que tienen una relación significativa con la unidad de descripción;

6. Área de Notas que contiene información especial y aquella otra que no ha podido incluirse en las demás áreas;

7. Área de Control de Descripción que contiene información del cómo, cuándo y quién ha elaborado la descripción archivística (ICA, 2002, pp. 13-14).

Los elementos obligatorios establecidos por la norma son seis (6) y corresponden al código de referencia, el título, las fechas extremas, el nivel de descripción, el volumen y el soporte que pertenecen al Área de Identificación y el nombre del o de los productor(es) perteneciente al Área de Contexto (ICA, 2000, p. 15). A nivel nacional, la estructura y el contenido de la información de cada uno de estos elementos han de ser enunciados de acuerdo con la Norma Uruguaya de Descripción Archivística (NUDA). Esta última, ha sido elaborada por la Comisión Interinstitucional para la elaboración de la, la cual estuvo integrada por profesionales nacionales y asesorada por profesionales internacionales, expertos en la materia (AGN, 2016, p. 13).

Al igual que la norma ISAD-G, dicha norma está dividida en siete (7) áreas que contienen los mismos elementos. Sin embargo, a diferencia de la primera, son ocho (8) los obligatorios para todos los niveles de descripción: a los seis, ya 
nombrados, se añaden el referido a Evaluación documental, perteneciente al Área de Contenido y Estructura, y el correspondiente a la Nota del Archivólogo, perteneciente al Área de Control de Descripción.

El archivólogo a cargo de la descripción archivística decidirá acorde con la necesidad y/o políticas institucionales los elementos, además de los obligatorios, que incluirá de acuerdo con el nivel de descripción (AGN, 2016, p. 21).

Además, al presente proyecto se inserta la función de evaluación documental desde la visión que pretende reafirmar los valores de las potenciales series documentales y establecer los criterios de evaluación conforme a la agrupación documental que nos convoca.

En relación con la evaluación documental, el Foro Iberoamericano de Evaluación de Documentos ${ }^{1}$ (FIED), sostiene que es "la función archivística que incluye las etapas de valoración, selección y disposición final de las series documentales" (Fenoglio, 2013, p. 46). A esta función corresponden tres etapas: valoración, selección y disposición final, en este caso adquiere especial interés la primera y segunda fase.

En lo que respecta al trabajo en valoración sobre documentación producida en períodos de represión, Antonio González Quintana (2009) plantea que tiene dos direcciones, por un lado, hacia el conocimiento del valor de las series documentales identificadas para la protección de los derechos individuales, así como el valor informativo como evidencia para la construcción de la historia del organismo represivo y el país. Y, por otro lado, realizar la selección de aquellos documentos que afectan a la persecución de los derechos humanos, lo que permite separarlos de la documentación de los organismos tradicionales que continúan en la democracia (González Quintana, 2009, p. 130).

En esta instancia, se define la valoración como la etapa en que se determinan los valores primarios y secundarios de las series documentales. El análisis y determinación de los valores primarios es aquel en el que "se establecen los parámetros de utilidad de los documentos y se facilita la identificación de los plazos de retención de los mismos, con base en las necesidades institucionales" (AGN, 2014, p. 21).

Asimismo, se considera relevante someter a esta documentación a una efectiva y formal evaluación documental, más allá de su indiscutible valor secundario. El 
objetivo es consolidar las prácticas archivísticas según las disposiciones vigentes en la materia a nivel nacional, desde la concepción del sistema nacional de archivos a través de la Ley $\mathrm{N}^{\circ} 18220$ del sistema nacional de archivos, del $20 \mathrm{de}$ diciembre de 2007.

También se destaca en cuanto al período al que se adscribe la documentación, el acta $\mathrm{n}^{\circ} 8$ del 24 de agosto de 2016, de la Comisión de evaluación documental de la Nación, que modifica el criterio de contenido estableciendo en su literal “d) Toda documentación que se encuentre en poder del Estado, que haya sido producida o recibida entre los años 1968 y 1985 se conservará íntegramente sin excepciones" (AGN-CEDN, 2016).

Además, se pretende identificar los valores de las series documentales considerando la contemporaneidad del contexto organizativo y normativo en que fueron producidas. En consecuencia, identificar los valores primarios que pudieron tener en su momento de creación y tramitación. Los valores secundarios, en cambio, ya están asignados en los criterios establecidos internacionalmente y aquellos proclamados por el Archivo General de la Nación y la CEDN.

\section{Objetivos}

El objetivo general se dirige a proponer pautas desde la investigación archivística para el posterior tratamiento adecuado a la identificación, representación descriptiva y evaluación de las imágenes digitalizadas de documentos microfilmados que integran los llamados Archivos Berrutti del Ministerio de Defensa Nacional del Uruguay.

Tiene como objetivos específicos los siguientes:

- Examinar los criterios de identificación archivística de especies y tipos documentales presentes en las imágenes digitalizadas de los archivos Berrutti.

- Determinar la representación de los documentos a través de sus imágenes digitales con una adaptación de las normas de descripción archivísticas, internacionales y la nacional.

- Establecer criterios para la identificación y valoración de las series documentales presentes en el universo digitalizado. 
- Caracterizar las funciones y actividades que dieron origen a las series documentales al tiempo de reconstruir los contextos de producción documental vinculados a los hechos de represión en el período de estudio delimitado.

Los rollos de microfilmes se encuentran en una de las cámaras de conservación del Archivo General de la Nación de Uruguay. Por su parte, en el año 2017 el Grupo de Trabajo por Verdad y Justicia (GTVJ) ${ }^{2}$ de la Presidencia de la República proporcionó al Proyecto Cruzar.uy copias digitalizadas de los microfilmes para el desarrollo de las actividades de extensión, enseñanza e investigación académicas.

\section{Metodología}

La metodología definida en esta investigación presenta un enfoque con método cualitativo de tipo exploratorio y descriptivo apropiado para cumplir con los objetivos planteados.

El aspecto exploratorio se considera importante, en tanto

Los estudios exploratorios sirven para preparar el terreno, y generalmente anteceden a los otros tipos. Los estudios exploratorios se efectúan, normalmente, cuando el objetivo es examinar un tema o problema de investigación poco estudiado o que no ha sido abordado antes. Se caracterizan por ser más flexibles y amplios en su metodología en comparación con los estudios descriptivos o explicativos (Batthyány y Cabrera, 2011, p. 33).

Además, se utilizará el aspecto descriptivo, ya que como expresan estas autoras

Los estudios descriptivos buscan caracterizar y especificar las propiedades importantes de personas, grupos, comunidades o cualquier otro fenómeno que sea sometido a análisis. Registran, miden o evalúan diversos aspectos, dimensiones o componentes de los fenómenos a investigar (2011, pp. 33-34).

Ambos tipos de diseño de investigación son necesarios, por un lado, porque se trata de una temática poco estudiada a nivel nacional y con referencias internacionales basadas en otro tipo de documentación de archivo no vinculada a los DDHH. Y, por otro lado, porque algunos objetivos están dirigidos a caracterizar y describir el fenómeno de producción documental y acopio de información en un período específico de la historia nacional. 
El proceso investigativo requiere el diseño y la aplicación de diferentes herramientas de relevamiento de datos en el marco de las funciones de identificación, evaluación y descripción archivísticas.

A partir de aquí se establecen las diferentes propuestas de instrumentos para el desarrollo del proceso investigativo y se justificará su ajuste a los objetivos establecidos para una mejor comprensión que conlleva un trabajo archivístico de estas características.

\section{Matriz de datos IdArchi-Cruzar.uy}

Uno de los objetivos es, como se mencionó, examinar los criterios de identificación archivística de especies y tipos documentales. Para ello, se requiere la visualización de cada imagen y la reunión de determinadas características que permitan el reconocimiento de especies e identificación de tipos documentales.

En consecuencia, se instrumenta una matriz de datos con el fin de sistematizar la información necesaria para aplicar las funciones archivísticas enunciadas como propósito del presente estudio $\mathrm{y}$, posteriormente, desarrollar el análisis documental recogido en los formularios ad hoc que se constituyen como productos de investigación en la materia.

Esta permite reunir la información sobre cada documento de archivo visualizado a partir de las imágenes digitales para luego comprenderlos en el contexto de acopio característico de las entidades militares y así poder llevar adelante el resto de las funciones archivísticas.

Los campos definidos de la matriz de datos son los siguientes:

\section{Cuadro $n^{\circ}$ 1: Matriz de datos de los Archivos Berrutti}

\begin{tabular}{|l|l|}
\hline \multicolumn{1}{|c|}{ Nombre de campo de dato } & \multicolumn{1}{c|}{ Descripción del dato } \\
\hline $\mathrm{N}^{\circ}$ de rollo & $\begin{array}{l}\text { Se corresponde con el número de rollo de microfilme en el } \\
\text { cual se encuentra la imagen digital objeto de identificación } \\
\text { primaria. }\end{array}$ \\
\hline Productor & $\begin{array}{l}\text { Refiere al nombre de la entidad productora del documento } \\
\text { de archivo representado en la imagen digital. Se consigna } \\
\text { desde la entidad mayor en orden decreciente jerárquico } \\
\text { hasta la que produjo el documento. }\end{array}$ \\
\hline Tipo documental & $\begin{array}{l}\text { Corresponde a la especie documental utilizada para tal } \\
\text { actividad en la producción del documento original. }\end{array}$ \\
\hline
\end{tabular}




\begin{tabular}{|l|l|}
\hline Actividad reflejada & $\begin{array}{l}\text { Refiere a la actividad administrativa o de inteligencia } \\
\text { característica de la época. }\end{array}$ \\
\hline $\begin{array}{l}\text { Serie documental / Unidad } \\
\text { documental }\end{array}$ & $\begin{array}{l}\text { Corresponde a la nominación de la serie documental } \\
\text { identificada primariamente a partir del carácter seriado } \\
\text { visualizado en las imágenes digitales de los documentos de } \\
\text { archivo. También, corresponde a la denominación de la } \\
\text { unidad documental simple o compuesta visualizada en las } \\
\text { imágenes. }\end{array}$ \\
\hline Número de inicio y fin & $\begin{array}{l}\text { Refiere al número de imagen que representa el inicio y al } \\
\text { número de fin de una unidad simple o compuesta, o al } \\
\text { conjunto de documentos de una serie documental. }\end{array}$ \\
\hline Observaciones & $\begin{array}{l}\text { Información pertinente y considerada relevante o aclaratoria } \\
\text { de los campos anteriores. }\end{array}$ \\
\hline
\end{tabular}

Fuente: elaboración propia.

\section{Propuesta de identificación archivística}

Unida al primer objetivo planteado, se debe también presentar una metodología de identificación de documentos basada en el reconocimiento de especies y tipos documentales requiere del análisis y determinación de algunos campos de información necesarios.

En este caso, se utilizará un segundo formulario para llevar a cabo la identificación archivística a partir de la información sistematizada en la matriz se diseñó un formulario con los siguientes campos conforme el método de tipología documental:

Cuadro $n^{\circ}$ 2: Identificación tipológica documental

\begin{tabular}{|c|c|}
\hline Nombre de campo & Descripción del campo \\
\hline Especie & $\begin{array}{l}\text { Se corresponde con el arquetipo de la información } \\
\text { distribuida en el documento de archivo visualizada en la } \\
\text { imagen. }\end{array}$ \\
\hline Actividad & $\begin{array}{l}\text { Refiere a la actividad administrativa o de inteligencia } \\
\text { característica de la época. }\end{array}$ \\
\hline Entidad productora & $\begin{array}{l}\text { Refiere al nombre de la entidad productora del documento } \\
\text { de archivo representado en la imagen digital. Se consigna } \\
\text { desde la entidad mayor en orden decreciente jerárquico } \\
\text { hasta la que produjo el documento. }\end{array}$ \\
\hline Tipo documental & $\begin{array}{l}\text { Corresponde a especie utilizada por la entidad al momento } \\
\text { de la producción documental en el marco de una actividad } \\
\text { específica. }\end{array}$ \\
\hline
\end{tabular}

Fuente: elaboración propia. 


\section{Propuesta de representación descriptiva: diseño de una ficha de descripción archivística ad hoc}

Un segundo objetivo propuesto en el proyecto de investigación está dirigido a adaptar las normas de descripción archivísticas (internacional y nacional), a instancia de las características específicas de la documentación objeto de estudio.

Para esta documentación especial y digital de derechos humanos se propone la elaboración de una ficha específica para la representación y descripción archivística a partir de la selección de campos tanto de la norma internacional ISAD-G como de la norma nacional NUDA y sus adaptaciones a las realidades archivísticas de nuestro país en la materia.

A ese respecto, se enuncian los elementos archivísticos que conformarán los campos de la ficha descriptiva ad hoc para las imágenes documentales que integran los denominados Archivos Berrutti (en adelante, FD-AB).

Cuadro $n^{\circ}$ 3: Estructura para la adecuación conceptual del elemento descriptivo

\begin{tabular}{|l|l|}
\hline Nombre del elemento de la FD-AB & $\begin{array}{l}\text { Es la denominación que adquiere el elemento } \\
\text { normalizado para la ficha descriptiva ad hoc de los } \\
\text { documentos que integran los llamados Archivos } \\
\text { Berrutti. }\end{array}$ \\
\hline Definición del elemento & $\begin{array}{l}\text { Es la definición del elemento seleccionado extraída } \\
\text { de una fuente normalizada o académica/ } \\
\text { especializada. }\end{array}$ \\
\hline Fuente de la definición & $\begin{array}{l}\text { Por ejemplo, ISAD-G, NUDA, Antonia Heredia, Cruz } \\
\text { Mundet, ICA, etc. }\end{array}$ \\
\hline Adecuación conceptual para FD-AB & $\begin{array}{l}\text { Se corresponde con la adaptación a la realidad } \\
\text { archivística nacional en materia de violaciones a los } \\
\text { derechos humanos acaecidas en el período de } \\
\text { actuación ilegítima y terrorismo de Estado. }\end{array}$ \\
\hline
\end{tabular}

Fuente: elaboración propia.

Los cuadros que se presentan a continuación, brindan la adecuación conceptual de cada elemento descriptivo seleccionado para la conformación de la FD-AB y según la estructura del cuadro $\mathrm{n}^{\circ} 3$. Con ellos, se establece el marco de conceptos teóricos que se utilizarán en cada instrumento y/o herramienta de investigación archivística para la obtención de los productos finales. Por ende, en cada cuadro se presenta uno a uno los elementos que comprenderán la ficha de descripción, la definición del elemento, la fuente de la que se extrajo la definición y una adecuación del concepto elaborada por el equipo de investigación. 
Cuadro $n^{\circ}$ 4: Adecuación conceptual del elemento procedencia.

\begin{tabular}{|l|l|}
\hline Nombre del elemento de la FD-AB & Procedencia \\
\hline Definición del elemento & $\begin{array}{l}\text { Es la relación existente entre los documentos de } \\
\text { archivo y las funciones que originan la necesidad de } \\
\text { tales documentos. }\end{array}$ \\
\hline Fuente de la definición & Heredia, 2011, p.151. \\
\hline Adecuación conceptual para FD-AB & $\begin{array}{l}\text { La procedencia se constituye con la trazabilidad de } \\
\text { las distintas forma de adquisición de la unidad de } \\
\text { descripción por la SDHPR (o sus figuras anteriores } \\
\text { organizativas), GTVJ, y Cruzar.uy. } \\
\text { Este campo se consigna/n la/s entidad/es de la que } \\
\text { procede y entre paréntesis curvos la data en formato } \\
\text { ISO 8601 (aaaa/mm/dd). }\end{array}$ \\
\hline
\end{tabular}

Fuente: elaboración propia.

Cuadro $n^{\circ}$ 5: Adecuación conceptual del elemento código de referencia

\begin{tabular}{|c|c|}
\hline Nombre del elemento de la FD-AB & Código de referencia: \\
\hline Definición del elemento & $\begin{array}{l}\text { Es un código único que se compone con los } \\
\text { siguientes elementos: } \\
\rightarrow \text { código del país que se corresponde con la norma } \\
\text { ISO } 3166-1 \text { (Uruguay: UY) } \\
\rightarrow \text { código alfabético de la Institución u otro } \\
\text { identificador único de su ubicación } \\
\rightarrow \text { código de la unidad de descripción } \\
\text { Para la separación de los elementos antes } \\
\text { mencionados se utilizará un guión -, sin dejar espacio } \\
\text { entre los mismos. }\end{array}$ \\
\hline Fuente de la definición & ISAD-G y NUDA \\
\hline Adecuación conceptual para FD-AB & $\begin{array}{l}\text { - Código de referencia de microfilmes: UY-AGN- } \\
\text { AH-OIDDHH-AB } \\
\text { - Código de referencia de microfilmes } \\
\text { digitalizados: UY-INDDHH-ARD-AB }\end{array}$ \\
\hline
\end{tabular}

Fuente: elaboración propia.

Cuadro $n^{\circ}$ 6: Adecuación conceptual del elemento título.

\begin{tabular}{|l|l|}
\hline Nombre del elemento de la FD-AB & Título \\
\hline Definición del elemento & $\begin{array}{l}\text { Su objetivo es denominar la unidad de descripción, en } \\
\text { caso de no poseer un título formal se puede utilizar un } \\
\text { título atribuido. }\end{array}$ \\
\hline Fuente de la definición & ISAD-G y NUDA \\
\hline Adecuación conceptual para FD-AB & $\begin{array}{l}\text { El título será atribuido por el grupo de investigación } \\
\text { IdArchi-Cruzar.uy como resultado del proceso de } \\
\text { identificación archivística. }\end{array}$ \\
\hline
\end{tabular}

Fuente: elaboración propia. 
Cuadro $n^{\circ}$ 7: Adecuación conceptual del elemento fecha(s).

\begin{tabular}{|l|l|}
\hline Nombre del elemento de la FD-AB & Fecha(s) \\
\hline Definición del elemento & $\begin{array}{l}\text { Son las que consignan el elemento fecha de la unidad } \\
\text { de descripción, se corresponde con la norma ISO } \\
8601 \text { siguiendo las pautas aaaa-mm-dd, utilizándose } \\
\text { como separador el guión. Cuando se consignen } \\
\text { fechas extremas, fecha de inicio y de conclusión, se } \\
\text { utilizará como separador una barra /. En caso de no } \\
\text { poseer fecha exacta el archivólogo estimará la misma } \\
\text { que se colocará entre paréntesis rectos o corchetes } \\
{[\ldots]}\end{array}$ \\
\hline Fuente de la definición & ISAD-G y NUDA \\
\hline Adecuación conceptual para FD-AB & $\begin{array}{l}\text { La fecha de la unidad de descripción corresponde a } \\
\text { la datas extremas de su original en soporte analógico. }\end{array}$ \\
\hline
\end{tabular}

Fuente: elaboración propia.

Cuadro $n^{\circ}$ 8: Adecuación conceptual del elemento nivel de descripción.

\begin{tabular}{|l|l|}
\hline Nombre del elemento de la FD-AB & Nivel de descripción \\
\hline Definición del elemento & $\begin{array}{l}\text { Se identifica el nivel de organización de la unidad } \\
\text { de descripción con respecto al fondo documental o } \\
\text { colección. Ej: fondo, subfondo, serie, subserie, } \\
\text { unidad documental compuesta, unidad documental } \\
\text { simple. }\end{array}$ \\
\hline Fuente de la definición & ISAD-G y NUDA \\
\hline Adecuación conceptual para FD-AB & $\begin{array}{l}\text { El nivel de la unidad de descripción es igual o } \\
\text { menor a serie documental, resultado del proceso de } \\
\text { identificación archivística. }\end{array}$ \\
\hline
\end{tabular}

Fuente: elaboración propia.

Cuadro $n^{\circ}$ 9: Adecuación conceptual del elemento soporte de la unidad de descripción.

\begin{tabular}{|l|l|}
\hline Nombre del elemento de la FD-AB & Soporte de la unidad de descripción \\
\hline \multirow{2}{*}{ Definición del elemento } & $\begin{array}{l}\text { Se identifica y describe el soporte de la unidad de } \\
\text { descripción. En caso de describir copias de } \\
\text { documentos que se hallan custodiados en otras } \\
\text { entidades archivísticas se indicará el soporte de las } \\
\text { copias. } \\
\text { Se señalará la existencia y localización de los } \\
\text { originales en el Área de documentación asociada. }\end{array}$ \\
\hline Fuente de la definición & ISAD-G y NUDA \\
\hline
\end{tabular}




\begin{tabular}{|l|l|}
\hline Adecuación conceptual para FD-AB & $\bullet \begin{array}{l}\text { Soporte primario de la unidad documental } \\
\text { original: papel }\end{array}$ \\
$\bullet \begin{array}{l}\text { Soporte secundario de la unidad documental } \\
\text { original: microfilme }\end{array}$ \\
$\qquad \begin{array}{l}\text { Soporte de la unidad documental copia de } \\
\text { microfilm: digital }\end{array}$ \\
\hline
\end{tabular}

Fuente: elaboración propia.

\section{Cuadro $n^{\circ}$ 10: Adecuación conceptual del elemento volumen de la unidad de} descripción.

\begin{tabular}{|l|l|}
\hline Nombre del elemento de la FD-AB & Volumen de la unidad de descripción \\
\hline Definición del elemento & $\begin{array}{l}\text { Se identifica y describe la extensión física, la } \\
\text { cantidad de documentos. En caso de describir copias } \\
\text { de documentos que se hallan custodiados en otras } \\
\text { entidades archivísticas se indicará la extensión, el } \\
\text { volumen y soporte de las copias. Ej: cantidad de } \\
\text { rollos, fotogramas, imágenes. Se señalará la } \\
\text { existencia y localización de los originales en el Área } \\
\text { de documentación asociada. }\end{array}$ \\
\hline Fuente de la definición & \begin{tabular}{l} 
ISAD-G y NuDA \\
\hline Adecuación conceptual para FD-AB
\end{tabular} \\
\hline
\end{tabular}

Fuente: elaboración propia.

Cuadro $n^{\circ}$ 11: Adecuación conceptual del elemento nombre del o de los productor(es).

\begin{tabular}{|l|l|}
\hline Nombre del elemento de la FD-AB & Nombre del o de los productor(es) \\
\hline Definición del elemento & $\begin{array}{l}\text { Se identificará el o los productores de la unidad de } \\
\text { descripción, el nombre(s) autorizado de la } \\
\text { institución o persona(s) responsable(s) de la } \\
\text { producción documental. En el caso que el productor } \\
\text { no pueda ser identificado se colocará el término } \\
\text { "Desconocido", si se estima o deduce el nombre se } \\
\text { colocará entre paréntesis rectos o corchetes [...]. }\end{array}$ \\
\hline Fuente de la definición & \begin{tabular}{l} 
ISAD-G y NUDA \\
\hline Adecuación conceptual para FD-AB
\end{tabular} \\
\hline
\end{tabular}

Fuente: elaboración propia. 
Cuadro $n^{\circ}$ 12: Adecuación conceptual del elemento Historia Institucional $/$ Reseña biográfica.

\begin{tabular}{|l|l|}
\hline Nombre del elemento de la FD-AB & Historia Institucional / Reseña biográfica \\
\hline Definición del elemento & $\begin{array}{l}\text { El objetivo es aportar una síntesis de la historia } \\
\text { institucional o datos biográficos del o de los } \\
\text { productores ubicar a la unidad de descripción en su } \\
\text { contexto histórico. Es de importancia cualquier dato } \\
\text { sobre el origen, evolución y otras denominaciones } \\
\text { del productor, fechas y lugares de existencia, } \\
\text { competencias o funciones. Si existiera información } \\
\text { adicional en otra fuente deberá citarse. }\end{array}$ \\
\hline Fuente de la definición & \begin{tabular}{l} 
ISAD-G y NUDA \\
\hline Adecuación conceptual para FD-AB
\end{tabular} \\
\hline
\end{tabular}

Fuente: elaboración propia.

Cuadro $n^{\circ}$ 13: Adecuación conceptual del elemento Historia Archivística.

\begin{tabular}{|l|l|}
\hline Nombre del elemento de la FD-AB & Historia archivística \\
\hline Definición del elemento & $\begin{array}{l}\text { En este campo se deberá proporcionar la } \\
\text { información de la historia de la unidad de } \\
\text { descripción que sea de relevancia para su } \\
\text { autenticidad, integridad, indicar cualquier hecho y/o } \\
\text { tratamiento archivístico que haya contribuido a } \\
\text { conformar su estructura y organización actual. } \\
\text { En caso de que se haya alterado la integridad de la } \\
\text { unidad de descripción se deberá especificar los } \\
\text { motivos. }\end{array}$ \\
\hline Fuente de la definición & \begin{tabular}{l} 
ISAD-G y NDA \\
\hline Adecuación conceptual para FD-AB
\end{tabular} \\
\hline & $\begin{array}{l}\text { Resumen de los procesos administrativos con } \\
\text { archivísticas y procesos de conversión de soportes. }\end{array}$ \\
\hline
\end{tabular}

Fuente: elaboración propia.

Cuadro $n^{\circ}$ 14: Adecuación conceptual del elemento forma de ingreso.

\begin{tabular}{|l|l|}
\hline Nombre del elemento de la FD-AB & Forma de ingreso \\
\hline Definición del elemento & $\begin{array}{l}\text { Se debe precisar la forma de ingreso, especificando } \\
\text { el origen desde donde fue remitida la unidad de } \\
\text { descripción, la fecha, el modo de adquisición o } \\
\text { transferencia. Entre las formas de adquisición } \\
\text { pueden señalarse: compra, donación, acuerdo de } \\
\text { partes, comodato, convenio de custodia, restitución } \\
\text { o transferencia. }\end{array}$ \\
\hline Fuente de la definición & ISAD-G y NUDA \\
\hline
\end{tabular}


Adecuación conceptual para FD-AB

Fecha y modo de adquisición de la unidad de descripción. La definición de la forma de ingreso alcanzará a las tradiciones documentales (originales y copias).

Fuente: elaboración propia.

Cuadro $n^{\circ}$ 15: Adecuación conceptual del elemento alcance y contenido.

\begin{tabular}{|l|l|}
\hline Nombre del elemento de la FD-AB & Alcance y contenido \\
\hline Definición del elemento & $\begin{array}{l}\text { Se procura proporcionar la información necesaria } \\
\text { referida a la unidad descripción brindando un } \\
\text { resumen de contenido acorde al nivel de } \\
\text { descripción. Se evitarán valoraciones o } \\
\text { interpretaciones subjetivas para los potenciales } \\
\text { usuarios. }\end{array}$ \\
\hline Fuente de la definición & \begin{tabular}{l} 
ISAD-G NUDA \\
\hline Adecuación conceptual para FD-AB
\end{tabular} \\
\hline $\begin{array}{l}\text { Análisis de contenido documental de la unidad de } \\
\text { descripción realizado por el grupo IdArchi- } \\
\text { Cruzar.uy. }\end{array}$ \\
\hline
\end{tabular}

Fuente: elaboración propia.

Cuadro $n^{\circ}$ 16: Adecuación conceptual del elemento evaluación documental.

\begin{tabular}{|c|c|}
\hline Nombre del elemento de la FD-AB & Evaluación documental \\
\hline Definición del elemento & $\begin{array}{l}\text { Se proporcionará información sobre cualquier } \\
\text { acción de valoración, selección y disposición final } \\
\text { (guarda permanente o eliminación) efectuada } \\
\text { especialmente si afectan de alguna manera a la } \\
\text { interpretación de la unidad de descripción. Se } \\
\text { indicará en caso de conocerse el responsable de } \\
\text { dicha acción. }\end{array}$ \\
\hline Fuente de la definición & ISAD-G y NUDA \\
\hline Adecuación conceptual para FD-AB & $\begin{array}{l}\text { Se formalizará el proceso de evaluación archivística } \\
\text { de manera que alcance a las tradiciones } \\
\text { documentales (originales y copias) de la unidad de } \\
\text { descripción: } \\
\text { - Microfilmes conservados en AGN; } \\
\text { - Copias digitales de microfilmes en INDDHH }\end{array}$ \\
\hline
\end{tabular}

Fuente: elaboración propia. 
Cuadro $n^{\circ}$ 17: Adecuación conceptual del elemento condiciones de acceso.

\begin{tabular}{|l|l|}
\hline Nombre del elemento de la FD-AB & Condiciones de acceso \\
\hline Definición del elemento & $\begin{array}{l}\text { Se deberá brindar información referida a las } \\
\text { condiciones de acceso a la unidad de descripción, } \\
\text { conforme a la Ley 18331 Protección de datos } \\
\text { personales y acción de Habeas Data y su Decreto } \\
\text { reglamentario 414/009 y la Ley 18381 Derecho de } \\
\text { Acceso a la Información Pública su decreto } \\
232 / 010 . \text { Si existe restricción de acceso se debe } \\
\text { indicar el tipo y el período de plazo de la misma, así } \\
\text { como la norma legal que lo rige. Si la restricción } \\
\text { fuera parcial deberá indicarse que parte se restringe. }\end{array}$ \\
\hline Fuente de la definición & \begin{tabular}{l} 
ISAD-G y NuDA \\
\hline Adecuación conceptual para FD-AB
\end{tabular} \\
\hline $\begin{array}{l}\text { Se consignarán las políticas de acceso, uso y } \\
\text { reutilización de la información en DDHH del } \\
\text { Uruguay y liberación de datos de las copias } \\
\text { digitales de microfilmes en INDDHH y en el } \\
\text { Proyecto Cruzar.uy. }\end{array}$
\end{tabular}

Fuente: elaboración propia.

Cuadro $n^{\circ}$ 18: Adecuación conceptual del elemento condiciones de reproducción.

\begin{tabular}{|l|l|}
\hline Nombre del elemento de la FD-AB & Condiciones de reproducción \\
\hline Definición del elemento & $\begin{array}{l}\text { Se deberá tener conocimiento sobre el tipo de } \\
\text { restricción relativa a la reproducción, uso y } \\
\text { divulgación de la unidad de descripción teniendo } \\
\text { en cuenta la norma jurídica correspondiente u otra } \\
\text { disposición. }\end{array}$ \\
\hline Fuente de la definición & \begin{tabular}{l} 
ISAD-G y NDA \\
\hline Adecuación conceptual para FD-AB
\end{tabular} \\
$\begin{array}{l}\text { Se consignarán las políticas de acceso, uso y } \\
\text { reutilización de la información en DDHH del } \\
\text { Uruguay y liberación de datos de las copias } \\
\text { digitales de microfilmes en INDDHH y en el } \\
\text { Proyecto Cruzar.uy. }\end{array}$ \\
\hline
\end{tabular}

Fuente: elaboración propia.

Cuadro $n^{\circ}$ 19: Adecuación conceptual del elemento características físicas y requisitos técnicos.

\begin{tabular}{|l|l|}
\hline Nombre del elemento de la FD-AB & Características físicas y requisitos técnicos \\
\hline Definición del elemento & $\begin{array}{l}\text { Se informará acerca de las características físicas o } \\
\text { requisito técnico que afecte el uso de la unidad de } \\
\text { descripción. Especificar el software necesario y el } \\
\text { hardware para acceder a la unidad de descripción. }\end{array}$ \\
\hline Fuente de la definición & ISAD-G y NUDA \\
\hline
\end{tabular}


Adecuación conceptual para FD-AB

Se consignarán las características de los sistemas informáticos utilizados para acceder a la unidad de descripción tanto en los INDDHH como en la órbita del Proyecto Cruzar.uy.

Fuente: elaboración propia.

Cuadro $n^{\circ} 20:$ Adecuación conceptual del elemento existencias y localización de originales.

\begin{tabular}{|l|l|}
\hline Nombre del elemento de la FD-AB & Existencias y localización de originales \\
\hline Definición del elemento & $\begin{array}{l}\text { Se informará sobre la existencia, localización y } \\
\text { disponibilidad de originales, en el caso que el } \\
\text { original encuentre en otra Institución, especificar } \\
\text { el lugar aportando datos que faciliten su } \\
\text { localización, se especificará las restricciones de } \\
\text { acceso a los originales. }\end{array}$ \\
\hline Fuente de la definición & \begin{tabular}{l} 
ISAD-G y NUDA \\
\hline Adecuación conceptual para FD-AB
\end{tabular} \\
$\begin{array}{l}\text { Se registrará la información de la existencia, } \\
\text { localización y disponibilidad de los microfilmes } \\
\text { originales en otras entidades que custodian fondos } \\
\text { de archivo u otras especializadas en derechos } \\
\text { humanos. }\end{array}$ \\
\hline
\end{tabular}

Fuente: elaboración propia.

Cuadro $n^{\circ} 21$ : Adecuación conceptual del elemento existencias y localización de copias.

\begin{tabular}{|l|l|}
\hline Nombre del elemento de la FD-AB & Existencias y localización de copias \\
\hline Definición del elemento & $\begin{array}{l}\text { Indicar la existencia de la localización y } \\
\text { disponibilidad de las reproducciones de la unidad de } \\
\text { descripción. Si la copia se encuentra en otra } \\
\text { Institución indicar el lugar y datos para su } \\
\text { localización. Se indicará si la reproducción es total } \\
\text { oparcial y si está autenticada. }\end{array}$ \\
\hline Fuente de la definición & \begin{tabular}{l} 
ISAD-G y NUDA \\
\hline Adecuación conceptual para FD-AB
\end{tabular} \\
$\begin{array}{l}\text { Secalización y disponibilidad de las de los } \\
\text { microfilmes en otras entidades que custodian } \\
\text { fondos de archivo u otras especializadas en } \\
\text { derechos humanos. }\end{array}$ \\
\hline
\end{tabular}

Fuente: elaboración propia. 
Cuadro $n^{\circ}$ 22: Adecuación conceptual del elemento punto de acceso.

\begin{tabular}{|l|l|}
\hline Nombre del elemento de la FD-AB & Punto de acceso \\
\hline Definición del elemento & $\begin{array}{l}\text { Término o palabra que es utilizado para la } \\
\text { identificación o localización del documento } \\
\text { requerido. }\end{array}$ \\
\hline Fuente de la definición & NOBRADE \\
\hline Adecuación conceptual para FD-AB & $\begin{array}{l}\text { Se corresponde con el término o palabra en lenguaje } \\
\text { natural (no controlado) que sirve para la } \\
\text { recuperación de la información de la unidad de } \\
\text { descripción. }\end{array}$ \\
\hline
\end{tabular}

Fuente: elaboración propia.

Cuadro $n^{\circ}$ 23: Adecuación conceptual del elemento notas.

\begin{tabular}{|l|l|}
\hline Nombre del elemento de la FD-AB & Notas \\
\hline Definición del elemento & $\begin{array}{l}\text { Tiene como objetivo asignar información que no } \\
\text { haya podido ser incluida en ninguna de las áreas } \\
\text { anteriores. }\end{array}$ \\
\hline Fuente de la definición & ISAD-G y NUDA \\
\hline Adecuación conceptual para FD-AB & $\begin{array}{l}\text { A la definición del elemento se incluye la } \\
\text { información contextual y/o de otras fuentes referida } \\
\text { a la unidad de descripción. }\end{array}$ \\
\hline
\end{tabular}

Fuente: elaboración propia.

\section{Cuadro $n^{\circ}$ 24: Adecuación conceptual del elemento nota del archivólogo.}

\begin{tabular}{|l|l|}
\hline Nombre del elemento de la FD-AB & Nota del archivólogo \\
\hline Definición del elemento & $\begin{array}{l}\text { Indicar quién o quiénes elaboraron la descripción } \\
\text { archivística. }\end{array}$ \\
\hline Fuente de la definición & ISAD-G y NUDA \\
\hline Adecuación conceptual para FD-AB & Grupo IdArchi-Cruzar.uy. \\
\hline
\end{tabular}

Fuente: elaboración propia.

\section{Cuadro $n^{\circ}$ 25: Adecuación conceptual del elemento fecha(s) de la(s)} descripción(es).

\begin{tabular}{|l|l|}
\hline Nombre del elemento de la FD-AB & Fecha(s) de la(s) descripción(es) \\
\hline Definición del elemento & $\begin{array}{l}\text { Indicar la fecha en que la descripción archivística } \\
\text { fue realizada o revisada. }\end{array}$ \\
\hline Fuente de la definición & ISAD-G y NUDA \\
\hline
\end{tabular}




\begin{tabular}{|l|l|}
\hline Adecuación conceptual para FD-AB & $\begin{array}{l}\text { Se consignará la fecha de publicación, } \\
\text { disponibilización, actualización y/o revisiones de } \\
\text { las FD-AB por parte del Grupo IdArchi-Cruzar.uy. }\end{array}$ \\
\hline
\end{tabular}

Fuente: elaboración propia.

Con la adecuación conceptual realizada se presenta en Apéndice 1 el Modelo de Ficha Descriptiva - Archivos Berrutti analógicos y en Apéndice 2 el Modelo de Ficha Descriptiva - Archivos Berrutti digitalizados.

\section{Propuesta de evaluación archivística: diseño de un formulario de identificación y valoración de documentos ad hoc}

En la misma línea que la propuesta dirigida a establecer una ficha ad-hoc para la descripción archivística, se establecerá un formulario de identificación y valoración documental (en adelante, FIVD) ad-hoc respetando las áreas y los elementos especificados por la norma ISAD-G y la NUDA. El objetivo es mantener criterios de normalización en todos los aspectos del quehacer archivístico: terminológico, instrumentos de trabajo, funciones y procedimientos, etc.

Como explican Lluis Cermeno Martorell y Elena Rivas Palá, los formularios de identificación y valoración documental en tanto herramienta archivística

Ofrecen a los archiveros una pauta sistemática y normalizada para la elaboración de las propuestas de evaluación. Facilitan el procedimiento de evaluación a las autoridades archivísticas. Integran información de carácter archivístico, jurídico-administrativo, técnico e informativo-histórico (Cermeno Martorell y Rivas Palá, 2011, p. 240).

El FIVD estará compuesto por seis áreas de información: contexto, identificación, características de la agrupación documental, relación con otra documentación, valoración, disposición y control. Por las características de la documentación se incorporarán campos de información y datos que permitan reconocer los contextos de producción, relaciones entre los documentos, y modificaciones en su estructura de contenido.

Este último punto, se desarrolla a instancias del objetivo que pretende establecer los criterios de valoración de las series documentales que se identifiquen.

Para los documentos de archivo, un criterio de valoración es una característica, un punto de referencia, que permite contar con una serie de guías o líneas directrices que ayudan al archivero de una organización a realizar propuestas para la definición de plazos de conservación (Franco Espiño y Pérez Alcazar, 2015). 
Además, la aplicación de la identificación y evaluación documental permiten el reconocimiento de las funciones y actividades de las cuales son producto los documentos de archivo.

\section{Reflexiones finales}

En esta instancia, de presentación del proyecto de investigación Id.ArchiCruzar.uy se arriba a reflexiones vinculadas con los pasos a seguir para alcanzar los objetivos y la importancia en la adecuación de las funciones archivísticas que se aplicarán sobre un grupo documental específico.

Uno de los principales propósitos del desarrollo de investigación archivística sobre documentos de archivos de la represión está dirigido a brindar el acceso a esa información específica en la materia en pos de la verdad y justicia. En este caso, a otras investigaciones alcanzadas en el marco del proyecto general Cruzar.uy, en tanto contribuye a dimensionar los contextos orgánicos y administrativos de creación de esta documentación para el reconocimiento de tipos y la identificación de las series, junto con la aproximación a las funciones o actividades objeto de la producción y acopio documental de la época.

La comprensión de estos aspectos de índole archivístico permite visualizar las características de los documentos de archivo, su autenticidad, integridad, fiabilidad e interrelacionamiento específico en organismos del estado uruguayo que llevaron adelante el proceso represivo de la época. En ese sentido, inscribe la aplicación del método de tipología documental en imágenes digitales de documentos acopiados en el marco de las funciones de información e inteligencia militar.

En lo referente a la función de descripción, la adecuación de normas internacionales y nacionales para un diseño de representación del universo documental específico abre un camino para la investigación necesaria en esa área de la archivística uruguaya.

De igual manera, la adaptación en los formularios de valoración documental posibilita el ejercicio de evaluación indirecto desde los conjuntos de imágenes digitales de esta documentación microfilmada característica que per se configura una conservación permanente. 
Por último, los resultados de la presente investigación aportarán productos en materia de identificación, evaluación y descripción archivísticas a la actual custodia de los rollos de microfilm originales, conservados en el Archivo General de la Nación.

\section{Referencias bibliográficas}

Archivo General de la Nación-Comisión de evaluación documental de la Nación. (2016). Acta No 08. Recuperado de http://agn.gub.uy/pdf/acta82016.pdf

Archivo General de la Nación. (2016). Norma Uruguaya de Descripción Archivística (NUDA). Recuperado de http://www.agn.gub.uy/pdf/nudacontapa.pdf

Batthyány, K. y Cabrera, M. (2011). Metodología de la investigación en ciencias sociales: apuntes para un curso inicial. Montevideo: Udelar, Departamento de Publicaciones, UCUR. Recuperado de https://www.colibri.udelar.edu.uy/jspui/bitstream/20.500.12008/9491/1/01 _FCS_Batthianny_2011-07-27-lowres.pdf

Bauer, C. S. (2014). Brasil e Argentina: ditaduras, desaparecimentos e políticas de memória. Porto Alegre: Medianiz. Recuperado de https://www.researchgate.net/publication/329987683_Brasil_e_Argentina ditaduras_desaparecimentos_e_politicas_de_memoria

Cermeno Martorell, L.; Rivas Palá, E. (2011). Valoración, selección y eliminación. En J. R. Cruz Mundet, Administración de documentos y archivos: textos fundamentales (pp. 215-272). Madrid: Coordinadora de Asociaciones de Archiveros. Recuperado de https://earchivo.uc3m.es/handle/10016/19730

Couture, C. (2015). A arquivística, os arquivistas e os arquivos no canadá. Acervo, 28 (2), pp. 147-163.

Da Silva Catela, L. (2002). El mundo de los archivos. En L. da Silva Catela y E. Jelin, Los archivos de la represión: documentos, memoria y verdad. (pp. 381-403). Madrid: Siglo XXI Editores. Recuperado de https://www.corteidh.or.cr/tablas/r29766.pdf

Fenoglio, N.; Mendoza Navarro, A.; Umaña Alpizar, R.; et all. (2013). Evaluación de documentos en Iberoamérica. Córdoba: Encuentro Grupo Editor.

Franco Spigno, B.; Pérez Alcázar, R. (2015). Modelo de Gestión de Documentos y Administración de Archivos (MGD) para la Red de Transparencia y 
Acceso a la Información (RTA): Directrices Instrumentos para la valoración. Recuperado de http://mgd.redrta.org/directrices-instrumentospara-la-valoracion/mgd/2015-01-23/181050.html

González Quintana, A. (2012). Políticas archivísticas para la defensa de los Derechos Humanos. Arch-e, 5, p. 213-223. Recuperado de http://www.juntadeandalucia.es/cultura/archivos_html/sites/default/conteni dos/general/revista/numeros/Numero_5/Galeria/03_05_13_GONZALEZ.p $\underline{\mathrm{df}}$

González-Quintana, A. (2009). Políticas archivísticas para la defensa de los derechos humanos. Santiago de Compostela: Red de Archivos Históricos de Comisiones Obreras. Recuperado de https://www.ica.org/sites/default/files/politicas_archivisticas_para_la_defe nsa_de_los_derechos_humanos.pdf

Heredia Herrera, A. (2011). Lenguaje y vocabulario archivísticos. Andalucía: Junta de Andalucía.

International Council on Archives. (2000). Norma Internacional de Descripción Archivística (ISAD-G). Recuperado de https://www.ica.org/sites/default/files/isad\%20g\%20SP.pdf

Llanes Padrón, D. (2016). La descripción archivística en los tiempos posmodernos: conceptos, principios y normas. Recuperado de https://www.marilia.unesp.br/Home/Publicacoes/la-description_ebook.pdf

López López, P. (2014, abril). Los archivos: garantes de derechos y de protección de la memoria histórica. Trabajo presentado en Jornadas El papel de los archivos en defensa de los derechos humanos y de la memoria histórica. Universidad Complutense de Madrid, Madrid. Recuperado de http://eprints.rclis.org/22900/1/ARCHIVOS-MEMHCA.pdf

Rabello, R. y Rodrígues, G. (2017). Documento, arquivo e formas de representação da realidade. En A. Cuevas Cerveró et al. (Coord.). Investigación en información, documentación y sociedad: perspectivas y tendencias. Madrid: Facultad de Ciencias de la Documentación, Universidad Complutense de Madrid (pp. 32-40). Recuperado de https://repositorio.unb.br/handle/10482/32960

Rodrigues, A. (2011). Identificação arquivística: subsídios para a construção teórica da metodologia na perspectiva da tradição brasileira. XII Encontro Nacional de Pesquisa em Ciencia da Informacao. Conferencia llevada a cabo en Distrito Federal Brasilia del 23 al 26 de octubre, Brasil. 
Uruguay. (2019, setiembre 18). Ley n 19.822: Cométese a la Institución Nacional de Derechos Humanos y Defensoría del Pueblo la búsquedas de las personas detenidas desaparecidas. Recuperado de https://www.impo.com.uy/bases/leyes/19822-2019

Uruguay. (2009, setiembre 18). Ley n 18.596: Reparación a las víctimas de la actuación ilegítima del Estado en el período comprendido entre el 13 de junio de 1968 y el 28 de febrero de 1985. Recuperado de http://www.impo.com.uy/bases/leyes/18596-2009\%20Ley\%20

\section{Notas}

1 El Proyecto Evaluación de documentos en Iberoamérica fue un proyecto presentado a la Comisión del Programa del Consejo Internacional de Archivos (ica) en 2009, el mismo fue aprobado durante cuatro años consecutivos, y los fied fueron los espacios de discusión y presentación de los avances del grupo de profesionales que asumieron el proyecto. Participaron representantes de Argentina, Brasil, España, Colombia, Costa Rica, México, Perú y Uruguay.

$\stackrel{2}{2}$ Con la extinción del gtvj y la promulgación de la ley $\mathrm{n}^{\circ} 19.822$ del 18 de setiembre de 2019, los acervos documentales pasan a la Institución Nacional de Derechos Humanos y Defensoría del Pueblo (en adelante, inddhh).

Los archivos y repositorios documentales existentes en la órbita del Grupo de Trabajo por Verdad y Justicia pasarán en su totalidad a la inddhh. (Ley n ${ }^{\circ}$ 19.822, artículo 11; Uruguay, 2019).

La Presidencia de la República continuará con las tareas de digitalización de toda la información existente sobre la materia y se la entregará a la inddhh que oficiará como repositorio. (Ley n 19.822, artículo 12; Uruguay, 2019).

Nota: El editor Mario Barité aprobó este artículo.

Nota de contribución: Orcesi se encargó fundamentalmente de la representación archivística en las partes del texto relacionadas con la función de descripción. López se encargó de la evaluación archivística en las partes del texto relacionadas 
con la función y los demás contenidos del artículo. Hernández se encargó de las tres archivísticas en las partes del texto relacionadas con la función y los demás contenidos del artículo.

\section{Apéndices}

\section{Apéndice 1 - Modelo de Ficha Descriptiva - Archivos Berrutti analógicos}

\begin{tabular}{|l|l|}
\hline \multicolumn{2}{|c|}{ Ficha Descriptiva - Archivos Berrutti analógicos } \\
\hline Procedencia & MDN \\
\hline Punto de acceso & $\begin{array}{l}\text { [término o palabra en lenguaje natural no } \\
\text { controlado que sirve para la recuperación de la } \\
\text { información de la unidad e descripción] }\end{array}$ \\
\hline
\end{tabular}

\begin{tabular}{|c|c|}
\hline & Área de id \\
\hline \multicolumn{2}{|l|}{ Código de referencia } \\
\hline Título & \\
\hline
\end{tabular}

UY-AGN-AH-OIDDHH-AB

[atribuido por el grupo de investigación IdArchi-Cruzar.uy como resultado del proceso de identificación archivística.]

\begin{tabular}{|l|l|l|l}
\hline Fecha/s & $\begin{array}{l}\text { datas extremas del original en soporte } \\
\text { analógico: papel }]\end{array}$ \\
\hline
\end{tabular}

\begin{tabular}{|l|l|}
\hline Nivel de descripción & $\begin{array}{l}\text { [Igual o menor a serie documental, resultado } \\
\text { del proceso de identificación archivística] }\end{array}$ \\
\hline Soporte documental & $\begin{array}{l}\text { Microfilme [incluir formatos y sus } \\
\text { características] }\end{array}$ \\
\hline Volumen & $\begin{array}{l}\text { [cantidad de fotogramas dentro del rollo de } \\
\text { microfilme/microfichas] }\end{array}$ \\
\hline
\end{tabular}

\section{Área de contexto}

Productor
[Denominación de la entidad productora de unidad de descripción en su soporte primario original (papel)]
Historia institucional
[Resumen de la historia de la entidad productora de la unidad de descripción] 


\section{Historia archivística}

Forma de ingreso
[Resumen de los procesos administrativos, eventos de transferencia archivística y conversión de soportes de la unidad de descripción]
En el año 2009 el Ministerio de Defensa transfiere a la Dirección del Archivo General de la Nación, un conjunto de documentos que pertenecieron al ESMACO durante los años de dictadura. Estos documentos se componen de 11 cajas con 1144 rollos de microfilm y su respaldo en 51 DVDs de material de archivo, proveniente de la Escuela de Inteligencia del Ejército. (Fuente: AGN, Guía de Fondos del Archivo General de la Nación, 2017, p. 93).

\section{Área de contenido y estructura}

\begin{tabular}{|c|c|}
\hline Alcance y contenido & \multirow{2}{*}{$\begin{array}{l}\text { [Resumen del contenido de acuerdo con el nivel } \\
\text { de descripción] }\end{array}$} \\
\hline & \\
\hline Evaluación documental & \multirow{2}{*}{$\begin{array}{l}\text { [Formalización del proceso de evaluación } \\
\text { archivística para la unidad de descripción] }\end{array}$} \\
\hline & \\
\hline \multicolumn{2}{|c|}{ Área de condiciones de acceso y uso } \\
\hline Condiciones de acceso & \multirow[b]{2}{*}{$\begin{array}{l}\text { [Resoluciones AGN n } 20 / 2011 \text { de } 29 \text { de julio de } \\
2011 \text { "Clasificación de Información Reservada" } \\
\text { y n }{ }^{\circ} 24 / 2012 \text { de } 31 \text { de julio de 2012: } \\
\text { "Rectificación y ampliación de clasificación de } \\
\text { información reservada". (Fuente: AGN, Guía de } \\
\text { Fondos del Archivo General de la Nación, } \\
\text { 2017, p. 103). }\end{array}$} \\
\hline & \\
\hline
\end{tabular}

\section{Condiciones de reproducción}

Para solicitar Información se debe completar un formulario que se brinda en la Recepción del AGN: calle Convención 1474, o a través de: "Trámites en línea" del Ministerio de Educación y Cultura: htpps://tramites.gub.uy/ampliados?id=4563

(Fuente: AGN, Guía de Fondos del Archivo General de la Nación, 2017, p. 103).

Características físicas y requisitos técnicos

[Características de los sistemas informáticos (software y hardware utilizados en el servicio de la OIDDHH]

\section{Área de documentación asociada}

Existencia y localización de originales
[Registro de la existencia, localización y disponibilidad de máster de microfilmes originales (de primera generación) en el Ministerio de Defensa Nacional] 


\section{Existencia y localización de copias}

[Registro de existencia, localización y disponibilidad de copias microfilmes (duplicado) en el Ministerio de Defensa Nacional o digitalizadas en otras entidades de DDHH]

\section{Área de notas}

Notas

[Información contextual y/o de otras fuentes referida a la unidad de descripción: ISAD-G; NUDA; ISO 3166; ISO 8601; Guía de Fondos del Archivo General de la Nación; etc.]

\section{Área de control de la descripción}

Nota del archivólogo Grupo IdArchi-Cruzar.uy como aporte al AGN

Fecha/s de la/s descripción/es

AAAAMMDD

Autoría de la FD-BD: Grupo IdArchi-Cruzar.uy

\section{Apéndice 2 - Modelo de Ficha Descriptiva - Archivos Berrutti digitalizados}

\section{Ficha Descriptiva - Archivos Berrutti digitalizados}

\begin{tabular}{|l|}
\hline Procedencia \\
Punto de acceso \\
\hline
\end{tabular}

\section{MDN}

[término o palabra en lenguaje natural no controlado que sirve para la recuperación dela información de la unidad e descripción]

\section{Área de identificación}

\begin{tabular}{|l|}
\hline Código de referencia \\
\hline Título \\
\hline
\end{tabular}

UY-AGN-AH-OIDDHH-AB

[atribuido por el grupo de investigación IdArchi-Cruzar.uy como resultado del proceso de identificación archivística.]

Fecha/s

[datas extremas del original en soporte analógico: papel]

Nivel de descripción

[Igual o menor a serie documental, resultado del proceso de identificación archivística] 


\section{Volumen}

[cantidad de fotogramas dentro del rollo de microfilme/microfichas]

\section{Área de contexto}

Productor

\section{Historia institucional}

Historia archivística

Forma de ingreso
[Denominación de la entidad productora de unidad de descripción en su soporte primario original (papel)]

\section{Área de contenido y estructura}

\section{Alcance y contenido}

Evaluación documental
[Resumen del contenido de acuerdo con el nivel de descripción]

[Formalización del proceso de evaluación archivística para la unidad de descripción]

\section{Área de condiciones de acceso y uso}

Condiciones de acceso
[Resoluciones AGN n²0/2011 de 29 de julio de 2011 "Clasificación de Información Reservada" y $\mathrm{n}^{\circ}$ 24/2012 de 31 de julio de 2012: "Rectificación y ampliación de clasificación de información reservada". (Fuente: AGN, Guía de Fondos del Archivo General de la Nación, 2017, p. 103).
Para solicitar Información se debe completar un formulario que se brinda en la Recepción del AGN: calle Convención 1474, o a través de: "Trámites en línea" del Ministerio de Educación y cultura: htpps://tramites.gub.uy/ampliados?id=4563 (Fuente: AGN, Guía de Fondos del Archivo General de la Nación, 2017, p. 103). 
Características físicas y requisitos técnicos

Existencia y localización de copias

\section{Área de notas}

\section{Notas}

\section{Área de control de la descripción}

Nota del archivólogo

Grupo IdArchi-Cruzar.uy como aporte al AGN
[Características de los sistemas informáticos (software y hardware utilizados en el servicio de la OIDDHH]

\section{Área de documentación asociada}

[Registro de la existencia, localización y disponibilidad de máster de microfilmes originales (de primera generación) en el Ministerio de Defensa Nacional]

[Registro de existencia, localización y disponibilidad de copias microfilmes (duplicado) en el Ministerio de Defensa Nacional o digitalizadas en otras entidades de DDHH]

Información contextual y/o de otras fuentes referida a la unidad de descripción: ISAD-G; NUDA; ISO 3166; ISO 8601; Guía de Fondos del

Archivo General de la Nación; etc.]

\begin{tabular}{|l|l|}
\hline \multicolumn{2}{|c|}{ Área de control de la descripción } \\
\hline Nota del archivólogo & Grupo IdArchi-Cruzar.uy como aporte al AGN \\
\hline Fecha/s de la/s descripción/es & AAAAMMDD \\
\hline
\end{tabular}

Autoría de la FD-BD: Grupo IdArchi-Cruzar.uy 